This is the accepted version of the article:

Neuderth P., Hille P., Schörmann J., Frank A., Reitz C., Martí-Sánchez S., De La Mata M., Coll M., Arbiol J., Marschall R., Eickhoff M.. Passivation layers for nanostructured photoanodes: Ultra-thin oxides on InGaN nanowires. J ournal of Materials Chemistry A, (2018). 6. : 565 - . 10.1039/c7ta08071a.

Available at: https://dx.doi.org/10.1039/c7ta08071a 


\title{
Passivation layers for nanostructured photoanodes: ultra- thin oxides on InGaN nanowires
}

\author{
Paula Neuderth ${ }^{1}$, Pascal Hille ${ }^{1,2}$, Jörg Schörmann ${ }^{1}$, Adina Frank ${ }^{1}$, Christian \\ Reitz $^{3}$, Sara Martí-Sánchez ${ }^{4}$, María de la Mata ${ }^{4}$, Mariona Coll ${ }^{5}$, Jordi Arbiol ${ }^{4,6}$, \\ Roland Marschall ${ }^{7}$, Martin Eickhoff ${ }^{1,2}$ \\ ${ }^{1}$ I. Physical Institute, Justus Liebig University Giessen, 35392 Giessen, Germany \\ ${ }^{2}$ Institute of Solid State Physics, University Bremen, 28359 Bremen, Germany \\ ${ }^{3}$ Institute of Nanotechnology (INT), Karlsruhe NanoMicro Facility (KNMF), Karlsruhe \\ Institute of Technology (KIT), 76344 Eggenstein-Leopoldshafen, Germany \\ ${ }^{4}$ Institut Català de Nanociència i Nanotecnologia, ICN2, CSIC and The Barcelona Institute of \\ Science and Technology (BIST), Campus UAB, Bellaterra, 08193 Barcelona, CAT, Spain \\ ${ }^{5}$ Institut de Ciencia de Materials de Barcelona, ICMAB-CSIC, Campus UAB, 08193 \\ Bellaterra, CAT, Spain \\ ${ }^{6}$ ICREA, Pg. Lluís Companys 23, 08010 Barcelona, Catalonia, Spain \\ ${ }^{7}$ Institute of Physical Chemistry, Justus Liebig University Giessen, 35392 Giessen, Germany
}

An experimental strategy for systematically assessing the influence of surface passivation layers on the photocatalytic properties of nanowire photoanodes by combining photocurrent analysis, photoluminescence spectroscopy and high resolution transmission electron microscopy with ${ }^{10}$ a systematic variation of sample structure and the surrounding electrolyte is demonstrated. Following

this approach we can separate the impact on recombination and transport processes of photogenerated carriers. We apply this strategy to analyze the influence of ultra-thin $\mathrm{TiO}_{2}, \mathrm{CeO}_{2}$ and $\mathrm{Al}_{2} \mathrm{O}_{3}$ coatings deposited by atomic layer deposition on the photoelectrochemical performance of $\operatorname{In}_{\mathrm{x}} \mathrm{Ga}_{1}{ }_{\mathrm{x}} \mathrm{N} / \mathrm{GaN} 15$ nanowire (NW) photoelectrodes. The passivation of surface states results in an increase of the anodic photocurrent (PC) by a factor of 2.5 for the deposition of $5 \mathrm{~nm} \mathrm{TiO}{ }_{2}$. In contrast, the PC is reduced for $\mathrm{CeO}_{2}$ - and $\mathrm{Al}_{2} \mathrm{O}_{3}$-coated NWs due to enhanced defect recombination in the passivation layer or increased band discontinuities. Furthermore, photoelectrochemical oxidation of the $\operatorname{In}_{\mathrm{x}} \mathrm{Ga}_{1} \mathrm{x} N / \mathrm{GaN} \mathrm{NW}$ photoelectrode is attenuated by the $\mathrm{TiO}_{2}$ layer and completely suppressed for a layer thickness of $7 \mathrm{~nm} 20$ or more. Due to efficient charge transfer from the $\mathrm{In}_{\mathrm{x}} \mathrm{Ga}_{1} \mathrm{x}$ NW core a stable $\mathrm{TiO}_{2}$-covered photoanode with visible light excitation is realized.

\section{Introduction}

In recent years semiconductor photocatalysis and especially the possibility of photoelectrochemical water splitting on semi- conductor surfaces has drawn interest as a clean method to produce hydrogen by conversion of solar energy. ${ }^{1,2}$ For a pho- toelectrochemical water splitting cell both cathode and anode materials need to be optimized, and at least one of the elec- trodes needs to be a photoelectrode. Typical photoanode materials for the demanding 4-hole oxidation of water are metal oxides like $\mathrm{TiO}_{2}$, as they are stable in aqueous solutions and efficiently enhance photo-activated electrode reactions. ${ }^{1,3}$ However, those materials leak in their high band gap of typically more than $3 \mathrm{eV}$, meaning only the ultraviolet regime of the solar 25 spectrum can be used to drive the photocatalytic reaction. 
The $\operatorname{In}_{\mathrm{x}} \mathrm{Ga}_{1} \mathrm{x}$ material system (InGaN) excellently matches the solar spectrum, as the band gap can be shi ed from the ultraviolet into the visible regime by adjusting the In-content $\mathrm{x}$ in the alloy, ${ }^{4,5}$ thus allowing the absorption in a broad spectral 30 range of the solar spectrum.

Planar group III-nitrides have been investigated with respect to their photocatalytical properties $^{6-12}$ and it has been shown that nanostructured anode materials, namely InGaN nanowires (NWs), can further enhance the solar-to-hydrogen conversion due a larger active surface area. ${ }^{13-16}$ Molecular beam epitaxy makes it possible to grow such NWs with high aspect ratio, high crystal quality, and low defect density in precisely designed structures. ${ }^{17}$

However, InGaN NW photoelectrodes suffer from a high loss of photo-generated carriers due to non-radiative surface recombination. A method to suppress such recombination processes is to improve the passivation of surface states by deposition of ultra-thin $\operatorname{lms}{ }^{18,19}$ Moreover, such surface coatings can have several additional effects on the lifetime and efficiency of a photoanode, depending on material parameters such as chemical composition, material quality or coating thickness. $\mathrm{TiO}_{2}$ has been shown to be an excellent protection layer for different types of (nanostructured) photoanodes. ${ }^{20-31}$ In this work we show that the performance of InGaN/GaN NW photoanodes under visible light excitation is significantly enhanced by deposition of an ultra-thin $\mathrm{TiO}_{2}$ coating. The requirements for a good passivation layer are assessed by comparison of $\mathrm{TiO}_{2}, \mathrm{CeO}_{2}$ and $\mathrm{Al}_{2} \mathrm{O}_{3}$ as coating materials. We systematically investigate the different contributions of loss processes to the photoelectrochemical performance of coated InGaN/GaN NW photoanodes, and the in uence of the coating thicknesses. Since photoexcitation of the InGaN at energies smaller than the band gaps of the coatings is possible and the band edge 10 positions of the coatings straddle the redox levels for water splitting, an efficient charge transfer from the InGaN core to the coating material allows the realization of a coated photoanode with visible light excitation in the InGaN core.
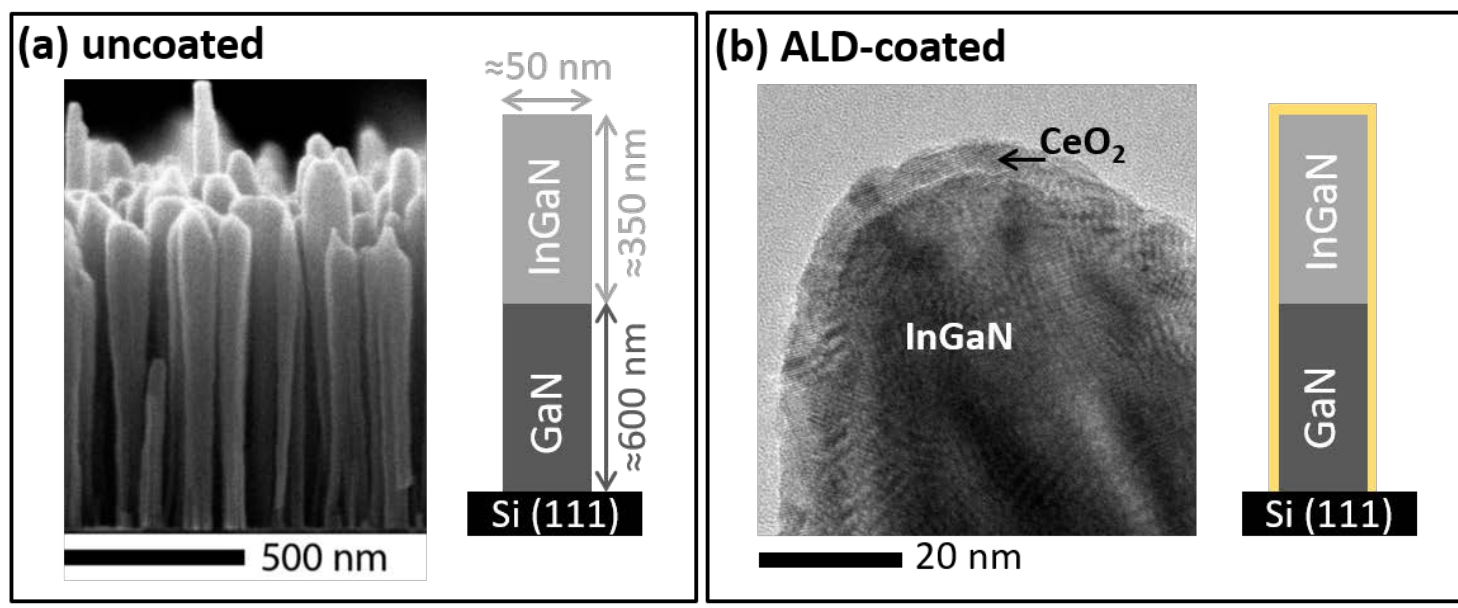

Figure 1 a) SEM-image and schematics with dimensions of uncoated InGaN/GaN nanowires. b) TEMimage and schematics of a $5 \mathrm{~nm}$ ALD coated InGaN/GaN NW (a $\mathrm{CeO}_{2}$ coated NW is shown exemplarily).

In Figure 2 transmission measurements of $5 \mathrm{~nm}$ thin ALD-films of the tree coating materials deposited on quartz glass are shown. At the excitation wavelength of $405 \mathrm{~nm}$ all coating materials are almost completely transparent $\left(T^{405 n m}{ }_{\mathrm{Al} 2 \mathrm{O} 3}=99 \% ; \quad \mathrm{T}^{405 \mathrm{~nm}}{ }_{\mathrm{TiO} 2}=98 \%\right.$; 
$\left.\mathrm{T}_{\mathrm{CeO} 2}^{405 \mathrm{~nm}}=97 \%\right)$. Hence, it can be assumed that a comparable amount of carriers is excited in the InGaN part of uncoated and coated samples. Excitation of carriers in the GaN base of the nanowires does not have to be considered.

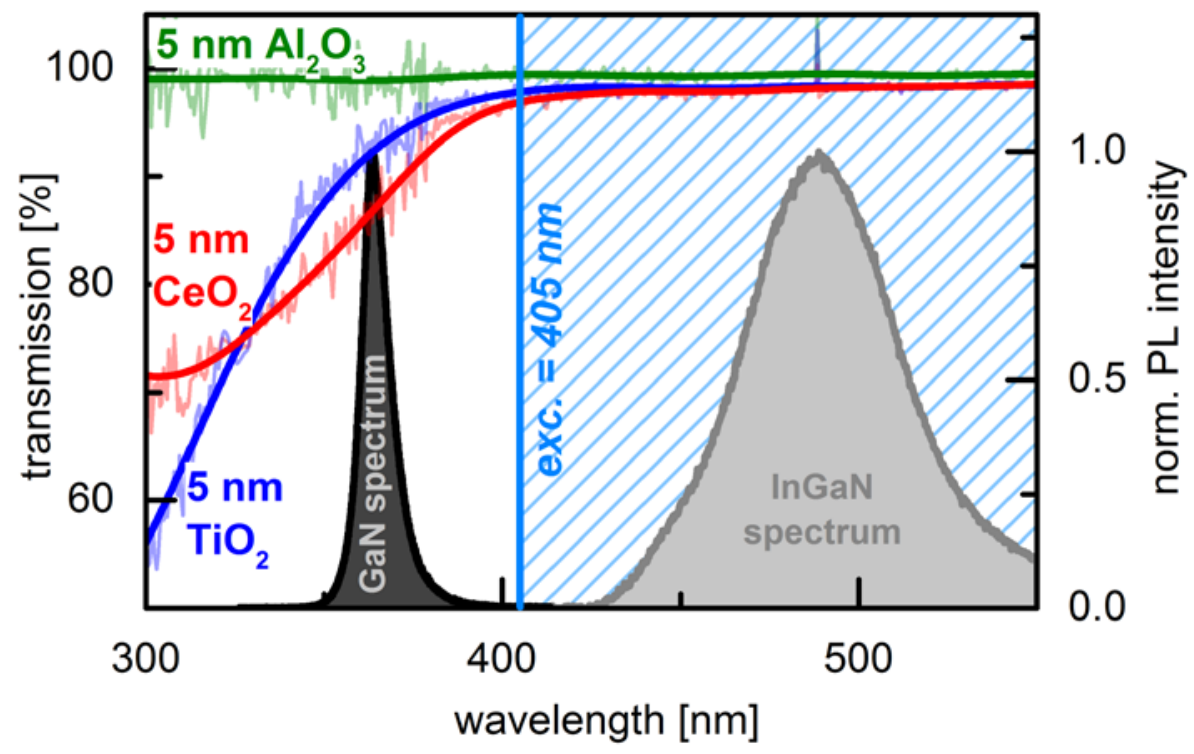

Figure 2 Transmission measurements of $5 \mathrm{~nm}$ thin atomic layer deposited $\mathrm{TiO}_{2^{-}}, \mathrm{CeO}_{2^{-}}$and $\mathrm{Al}_{2} \mathrm{O}_{3^{-}}$ films on quartz glass compared to the excitation wavelength of $405 \mathrm{~nm}$ and the PL emission of GaN and InGaN.

\section{Photoelectrochemical investigation}

For photoelectrochemical investigation (photoluminescence, photocurrent and open circuit potential measurements) the sample was mounted in a cell with a continuous electrolyte flow, realized by a peristaltic pump.

As standard electrolyte a $1 \mathrm{M}$ phosphate buffer solution at $\mathrm{pH} 8$ with a conductivity of $100 \mathrm{mS} / \mathrm{cm}$ was used. For a hole scavenger containing electrolyte $1 \mathrm{M}$ of $\mathrm{Na}_{2} \mathrm{SO}_{3}$ was added to the solution. A pH-value of 8 and a conductivity of $100 \mathrm{mS} / \mathrm{cm}$ were adjusted for comparability.

An external bias was applied by connecting the sample as working electrode in a threeelectrode setup with an $\mathrm{Ag} / \mathrm{AgCl}$ reference electrode and a platinium counter electrode. Ohmic contacts on the backside of the conductive silicon substrates were deposited by thermal evaporation of $\sim 50 \mathrm{~nm} \mathrm{Al}$ and $\sim 150 \mathrm{~nm} \mathrm{Ag}$. A potentiostat was used to apply a controlled bias.

For photo-excitation of the NW structures a $405 \mathrm{~nm}$ laser diode was fiber-coupled to the chamber through a quartz window on top. The incident excitation power at the electrolyte surface was determined to $29 \mathrm{~mW}$ using a power meter. 
For photoluminescence (PL) measurements the light emitted by the nanowire sample is fibercoupled to a QWave USB spectrometer (rgb lasersystems). Two pass filters at 435 and 425 nm were used to suppress the laser line.

Simultaneous measurement of the photocurrent (PC) was facilitated using a Keithley 2700 multimeter connected between potentiostat and working electrode. A shutter was placed in front of the laser diode, to make a switching between dark and illuminated intervals in transient measurements possible.

The open circuit potential was measured after an equilibration time of $20 \mathrm{~min}$ in dark and after 5 min under illumination, respectively.

The chopped light voltammetry analysis’s shown in Figure 9 and Figure 12 were performed in a photoelectrochemistry setup by Zahner, using a $523 \mathrm{~nm}$ LED (0.7 mW excitation power on the sample) for excitation and a static 3-electrode measurement cell without electrolyte flow.

All measurements were performed at room temperature.

\section{Results and Discussion}

Sample properties

The investigated samples consist of InGaN/GaN NWs (cf. scanning electron microscopy image (SEM) and schematic structure in Fig. 1a), which were coated with 2-15 nm thin lms of $\mathrm{TiO}_{2}, \mathrm{CeO}_{2}$ and $\mathrm{Al}_{2} \mathrm{O}_{3}$ respectively using atomic layer deposition (ALD) (cf. high resolution transmission electron images (HRTEM) and schematic structure in Fig. 1b). All NW samples show complete conformal coverages with homogeneous film thickness. Upon film deposition the shape of the nanowire remains unchanged, only the diameter is increased by twice the film thickness, resulting also in a decrease in average distance between the nanowires of the ensemble. Nevertheless, the nanowires remain sufficiently separated to allow free access of the electrolyte to their lateral facets.

For photoexcitation of carriers in the InGaN part of the NWs a wavelength of $405 \mathrm{~nm}$ was used. In Fig. 2 transmission measurements of $5 \mathrm{~nm}$ thin ALD lms of the three coating materials deposited on quartz glass are shown. At $405 \mathrm{~nm}$ all coating materials are almost completely transparent $\left(\mathrm{T}_{405} \mathrm{~nm}, \mathrm{Al}_{2} \mathrm{O}_{3} 1 / 499 \% ; \mathrm{T}_{405} \mathrm{~nm}, \mathrm{TiO}_{2} 1 / 498 \%\right.$; $\left.\mathrm{T}_{405} \mathrm{~nm}, \mathrm{CeO}_{2} 1 / 497 \%\right)$. Hence, it can be assumed that a comparable amount of carriers is excited in the InGaN part of uncoated and coated samples. Excitation of carriers in the GaN base of the NWs does not have to be considered. 
(a) uncoated

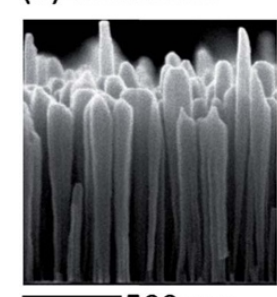

$500 \mathrm{~nm}$

(b) ALD-coated

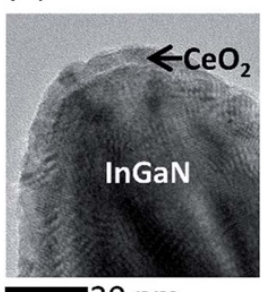

$20 \mathrm{~nm}$
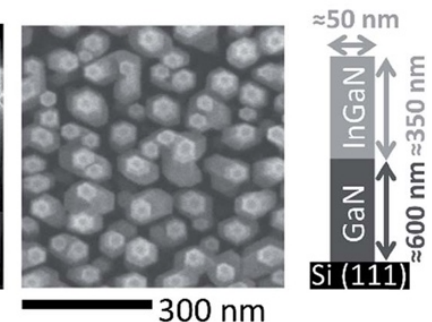

$300 \mathrm{~nm}$

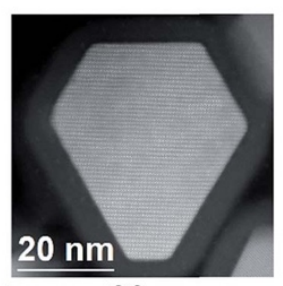

$20 \mathrm{~nm}$

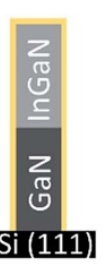

Fig. 1 (a) SEM-images in side- and top-view and schematics with dimensions of uncoated InGaN/GaN NWs; (b) STEM-images in side view and cross-section (exemplarily shown are: left: HRTEM image of $\mathrm{CeO}_{2}$-coated NW; right: HAADF STEM image of the cross-section of a $\mathrm{TiO}_{2}$-coated NW) and schematics of a $5 \mathrm{~nm}$ ALD coated InGaN/GaN NW.

\section{Uncoated InGaN/GaN NW photoanodes}

In Fig. 3a an example of a bias-dependent photocurrent (PC) measurement of an uncoated InGaN/GaN NW sample under chopped light irradiation is shown. For bias voltages more anodic than $270 \mathrm{mV}$ vs. $\mathrm{Ag} / \mathrm{AgCl}$ a current is observed in the illuminated intervals. This PC increases with increasing bias, leading to a PC density of $400 \mathrm{~mA} \mathrm{~cm}{ }^{2}$ at $900 \mathrm{mV}$. For bias voltages below $270 \mathrm{mV}$ a current in the opposite direction can be observed both in illuminated and dark intervals. The bias dependence of the PC can be explained by the adjustment of the surface band bending due to the external bias.

To analyze the stability of the NW PC, repeated PC measurements at a xed anodic bias of $700 \mathrm{mV}$ for illumination intervals of $30 \mathrm{~min}$ separated by dark intervals of $10 \mathrm{~min}$ were performed (Fig. 3b). The bias of $700 \mathrm{mV}$ was chosen as it results in a stable photocurrent without degradation of the NWs or the respective coatings. In the transient measurement a decrease in PC over time is observed which stabilizes after approximately $1 \mathrm{~h}$, id est after 1-2 illumination intervals, at a lower PC than the initial one (dotted red line in Fig. 3b).

The application of an anodic bias to InGaN in electrolytes under illumination is known to cause oxidation of the NWs. The formation of an $\left(\operatorname{In}_{x} \mathrm{Ga}_{1 x}\right)_{2} \mathrm{O}_{3}$ layer causes a large band offset at the $\left.\operatorname{In}_{\mathrm{x}} \mathrm{Ga}_{1}{ }_{\mathrm{x}} \mathrm{N} /\left(\mathrm{In}_{\mathrm{x}} \mathrm{Ga}_{1}\right)_{2}\right)_{2} \mathrm{O}_{3}$ interface and a suppression of carrier transfer into the electrolyte, which leads to the perma- nent decrease of the $\mathrm{PC}^{32}$ (red dotted line in Fig. 3b). Once the oxide film is closed no further oxidation of the InGaN occurs and a stable PC of the InGaN NW electrodes is observed. The overshoot at the beginning of each illuminated interval (Fig. 3b) is typical for immediate transport of surface near carriers into the electrolyte a er rst light excitation, the decay is caused by the recombination and trapping of following carriers. 


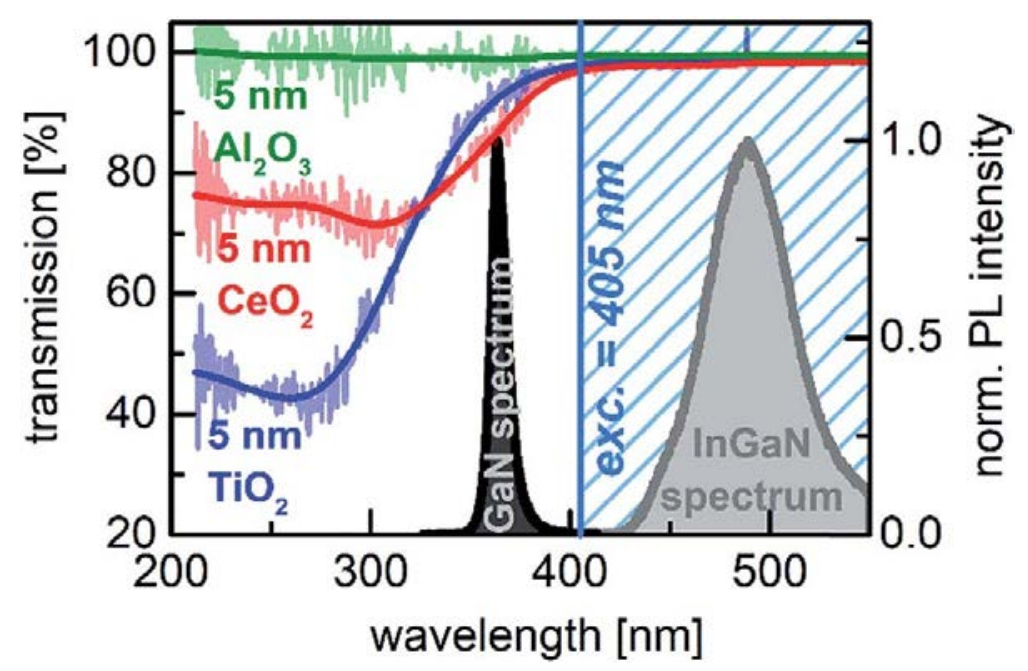

Fig2. Transmission measurements of $5 \mathrm{~nm}$ thin $\mathrm{ALD} \mathrm{TiO} 2, \mathrm{CeO}_{2}$ and $\mathrm{Al}_{2} \mathrm{O}_{3}$ films on quartz glass compared to the excitation wavelength of $405 \mathrm{~nm}$ and the photoluminescence emission of $\mathrm{GaN}$ and InGaN.
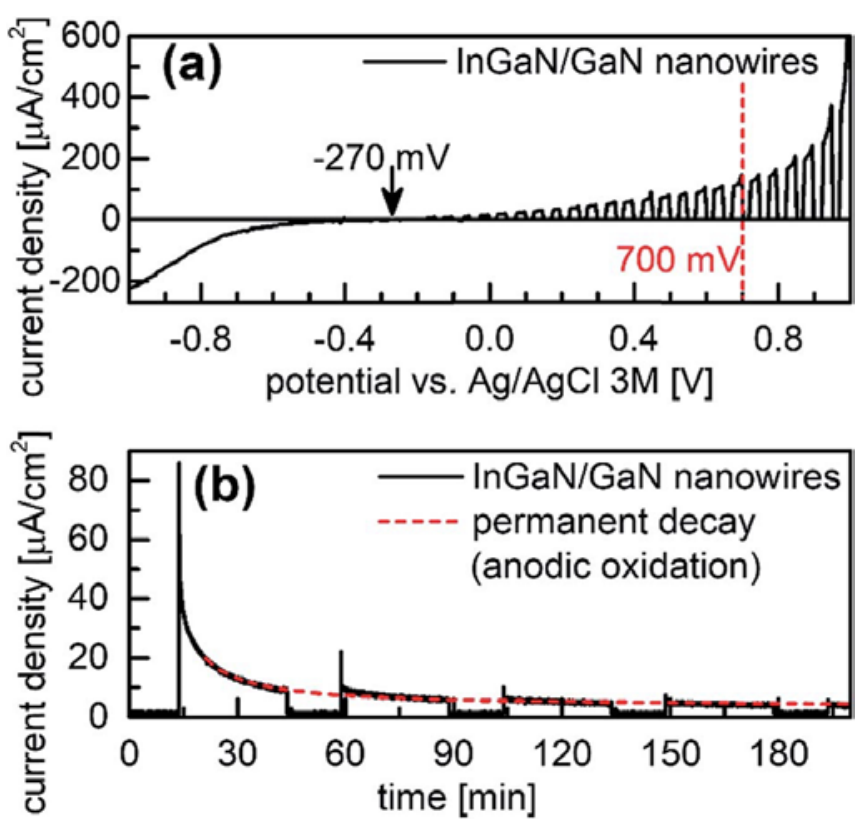

Fig. 3 PC measurements on uncoated InGaN/GaN NWs. (a) Bias- dependent chopped light PC measurement; (b) time-dependent PC measurement at a fixed anodic bias of $700 \mathrm{mV}$.

\section{Influence of $5 \mathrm{~nm}$ oxide coatings}

The PC of InGaN nanowires coated with $5 \mathrm{~nm}$ thin films of $\mathrm{TiO}_{2}, \mathrm{CeO}_{2}$ or $\mathrm{Al}_{2} \mathrm{O}_{3}$ was analyzed in comparison to an uncoated reference sample (Figure $\mathbf{4 b}$-d) at a fixed anodic bias of $700 \mathrm{mV}$ using the same measurement sequence as above. For each of the measurements the second illuminated interval is shown, to discuss the transients in their stable condition where no further anodic oxidation occurs.

All coated samples still show significant PCs. However, the influence of the coating strongly depends on the coating material. In comparison to the reference sample an increase of 
photocurrent intensity by a factor of 2.5 after deposition of $5 \mathrm{~nm} \mathrm{TiO}_{2}$ is observed (Figure 4a). In contrast, $\mathrm{CeO}_{2}$ and $\mathrm{Al}_{2} \mathrm{O}_{3}$ coverages with the same thickness lead to a PC decrease by a factor of 0.9 (Figure $\mathbf{4 b , c}$ ), despite the fact that a passivation of surface states would be expected for all three materials.

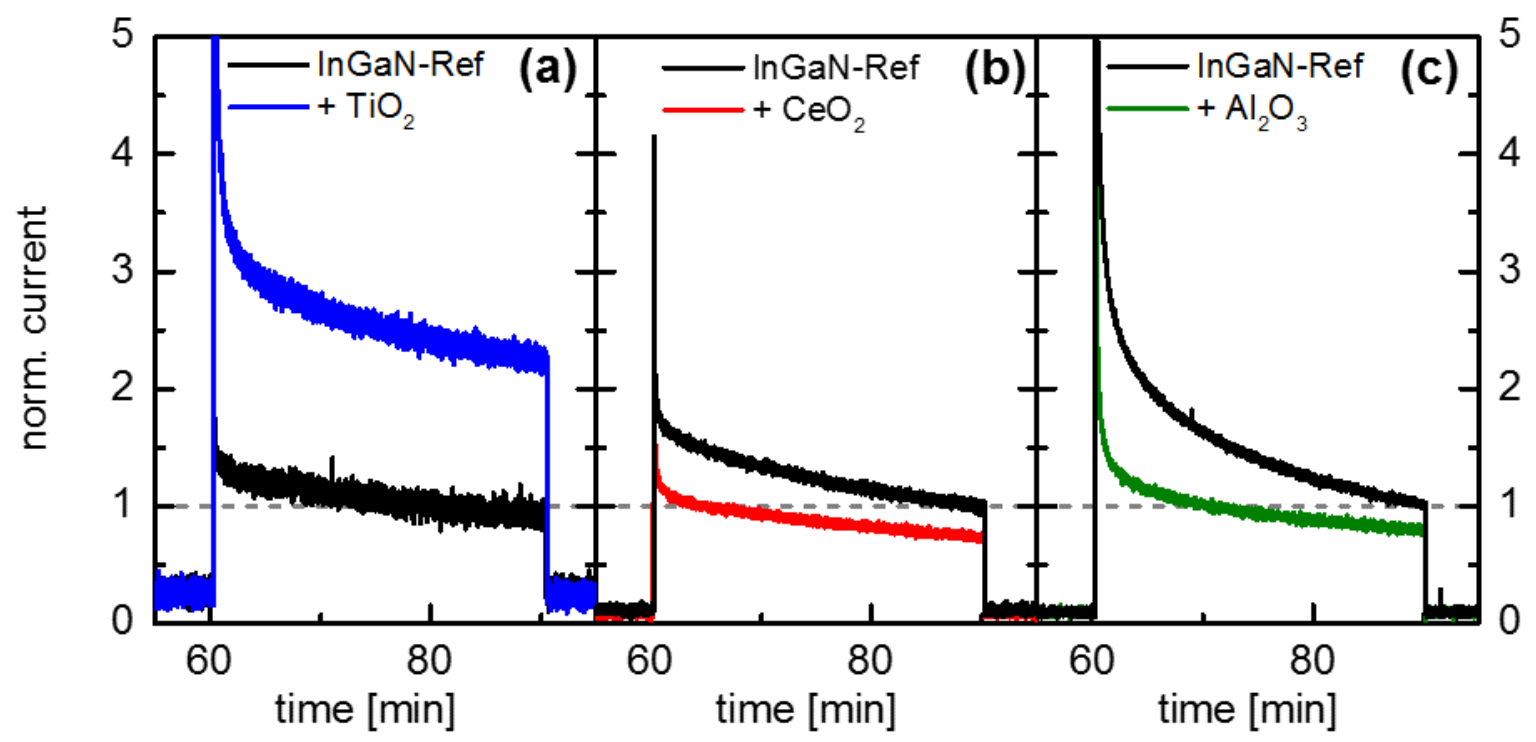

Figure 3 Influence of different ALD-coatings on the photocurrent of InGaN/GaN nanowires: Photocurrent measurements of $\mathrm{TiO}_{2^{-}}, \mathrm{CeO}_{2^{-}}$and $\mathrm{Al}_{2} \mathrm{O}_{3}$-coated nanowires at fixed $700 \mathrm{mV}$ anodic bias normalized to an uncoated reference piece (black) of the same sample are shown.

To elucidate the origin for the different influence of the three coating materials on the PC, we investigated the transport of photo-excited carriers through the coating layer.

To contribute to the photocurrent carriers excited in the InGaN part of the nanowire need to be transported into the electrolyte and can undergo different recombination processes, schematically shown in Figure 5 for uncoated and coated samples.

In the case of uncoated nanowires the photocurrent is mainly reduced by radiative recombination in the InGaN core (process 1) and by non-radiative surface recombination (process 2) [25]. For coated nanowires both can be affected by formation of the InGaN NW/oxide interface (process 1', 2'). Moreover, defect recombination within the ultrathin coating layer (process 3) and surface recombination at the oxide/electrolyte interface (process 4) result in further losses. Radiative recombination in the coating can be neglected, as no band-to-band excitation within the coating takes place and the simultaneous transfer of electrons and holes from the InGaN is suppressed due to band discontinuities.

To result in an enhanced photocurrent PC' the reduction of the recombination rate due to passivation of surface states (process 2 -> process 2') must overcompensate the additional 
loss processes 3 and 4 . In the following, the 4 processes are investigated separately for the different coating materials.

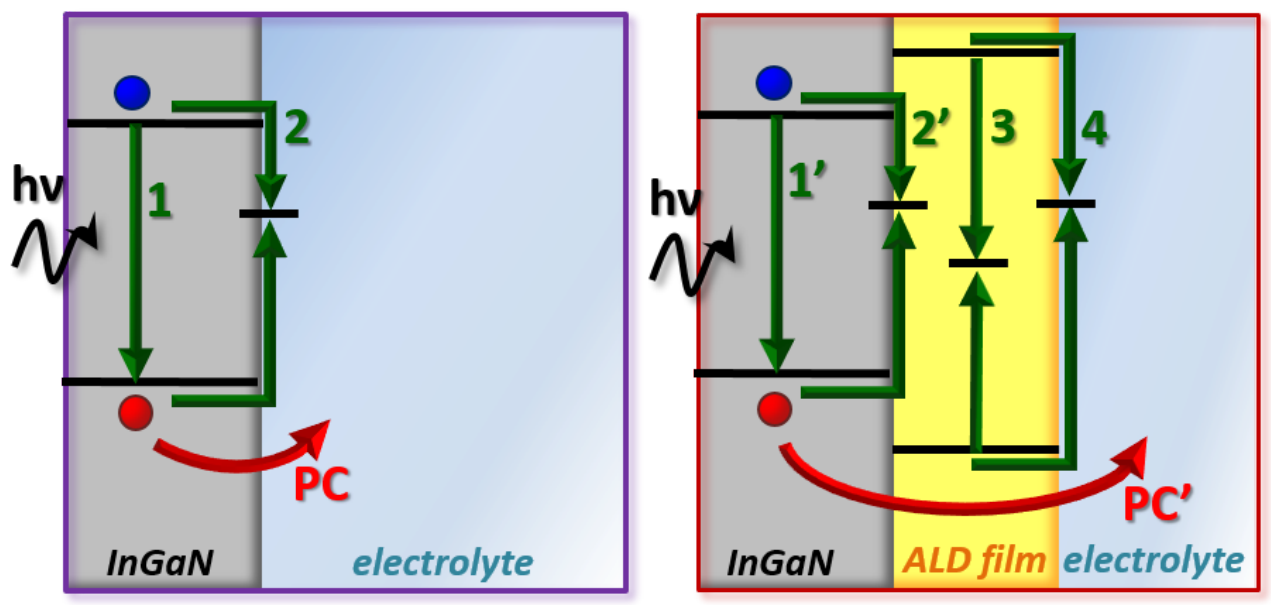

Figure 4 The reduction of photocurrent (PC; red arrow) due to different recombination processes (green arrows) is schematically shown for uncoated (left) and coated (right) InGaN/GaN nanowires. Loss processes: 1/1' radiative recombination within InGaN core, 2/2' recombination at the InGaN surface, 3 recombination in the coating, 4 surface recombination at the coating/electrolyte interface.

Process 1 (resp. 1') in Figure 5 is the radiative recombination of excited electrons and holes in the InGaN NW and can be measured by photoluminescence (PL) measurements, which can be carried out simultaneously with the PC analysis. The PL intensities of the coated samples normalized to their uncoated reference samples at $700 \mathrm{mV}$ anodic bias are compared in Figure 6a-c. The influence of the ALD coatings on the PL-intensity depends on the respective material: Whereas the PL-intensity of InGaN nanowires is slightly reduced by a $\mathrm{TiO}_{2}$ coating (x 0.8) it remains almost constant for the $\mathrm{CeO}_{2}$ coating, while a strong enhancement is found for the $\mathrm{Al}_{2} \mathrm{O}_{3}$ coating (x1.6). Hence, the suppressed photocurrent due to $\mathrm{Al}_{2} \mathrm{O}_{3}$ coating is accompanied by an enhancement of radiative recombination, demonstrating that these are competing processes. This is supported by the data for the $\mathrm{TiO}_{2}$ coating, where an increased PC and a decreased PL intensity are observed, whereas both entities remain almost unaffected for the $\mathrm{CeO}_{2}$ coating.

The proportion of PL and PC as competitive processes is mainly given by the degree of charge separation, which is defined by the InGaN/coating interface and therefore by the band bending and the band offset.

The band bending can be controlled by the applied bias, giving a contrary bias dependence for the PL and PC of uncoated, $\mathrm{TiO}_{2}$-coated and $\mathrm{CeO}_{2}$-coated samples. However, in the case of $\mathrm{Al}_{2} \mathrm{O}_{3}$ almost no bias dependence was observed for PL and PC (see supplemental information 2) indicating that carriers cannot be transferred across the $\mathrm{InGaN} / \mathrm{Al}_{2} \mathrm{O}_{3}$ interface by band transfer. 
Literature values for the band alignment of the different involved materials are compared in Figure 6d [4,5,20,22,23,26]. The conduction band positions of $\mathrm{CeO}_{2}$ and $\mathrm{InGaN}$ material with an indium concentration of 25\% (extracted from PL analysis) are on the same potential and the conduction band of $\mathrm{TiO}_{2}$ is even energetically below that of $\operatorname{InGaN}(0.2 \mathrm{eV})$. The valence band positions of $\mathrm{CeO}_{2}$ and $\mathrm{TiO}_{2}$ are slightly below those of the $\mathrm{In}_{25} \mathrm{Ga}_{75} \mathrm{~N}\left(\mathrm{TiO}_{2}: 0.8\right.$ $\mathrm{eV} ; \mathrm{CeO}_{2}: 0.6 \mathrm{eV}$ ). For photogenerated holes this implies the formation of a small potential barrier that can easily be overcome upon illumination. If the average In-content of $10 \%$ estimated by XRD-analysis is taken into account (see dotted lines in Figure 6d), the InGaN bandgap would be larger, resulting in $0.1 \mathrm{eV}$ smaller valence band offsets for all materials. On the contrary, the valence (conduction) band offset between InGaN and $\mathrm{Al}_{2} \mathrm{O}_{3}$, is $3.3 \mathrm{eV}$ (3.0 $\mathrm{eV}$ ). Hence, only defect-assisted transport or tunneling of photo-generated holes into the $\mathrm{Al}_{2} \mathrm{O}_{3}$-coating is possible while otherwise the carrier confinement in the InGaN core is significantly enhanced, leading to an increased radiative recombination rate inside the NW. The assumption of suppressed band transfer for $\mathrm{Al}_{2} \mathrm{O}_{3}$ coated $\mathrm{InGaN}$ nanowires is supported by the fact that PL and PC are independent of the applied bias in this case.
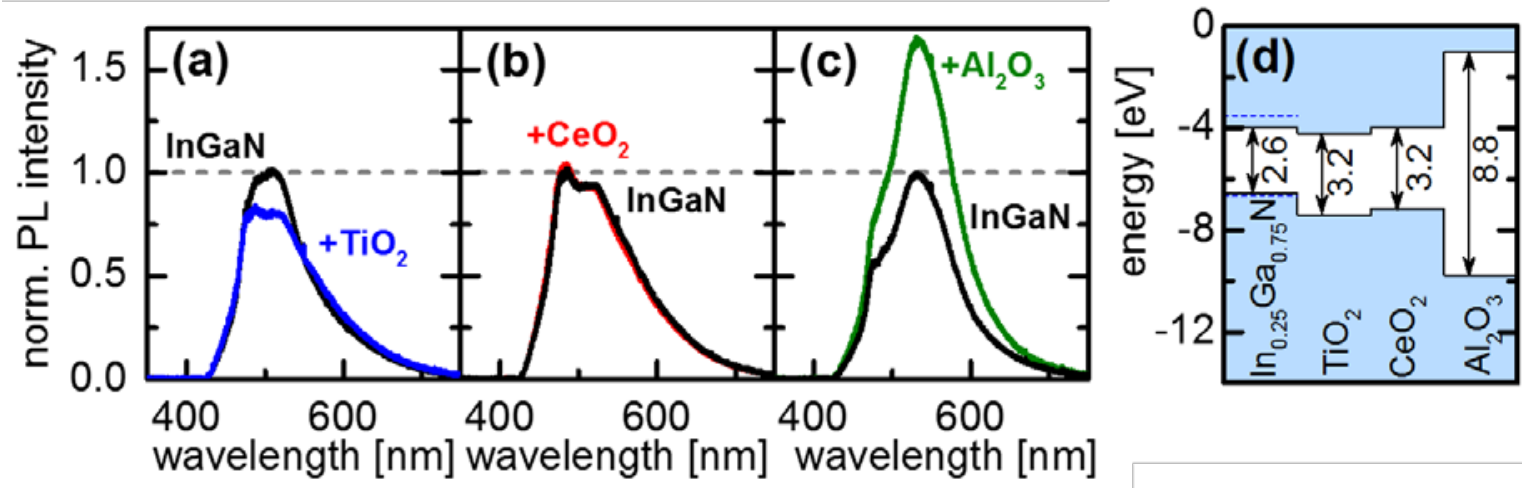

Figure 5 (a-c) Photoluminescence spectra of $\mathrm{TiO}_{2-}$, $\mathrm{CeO}_{2}$ - and $\mathrm{Al}_{2} \mathrm{O}_{3}$-coated nanowires normalized to the spectra of uncoated reference pieces from the same sample. Spectra are taken at $700 \mathrm{mV}$ anodic bias. (d) Band alignment of the coating materials compared to $\operatorname{In}_{x} G a_{1-x} N$ with an In-concentration of $x=0.25$ from PL measurement (solid lines) and $x=0.1$ from XRD measurement (dotted lines); band position values for $T=0 \mathrm{~K}[4,5,20,22,23,26]$.

Photoluminescence intensity and band alignment are comparable for $\mathrm{TiO}_{2}$ - and $\mathrm{CeO}_{2}$-coatings on InGaN nanowires. However, a significant increase of the PC was observed for the $\mathrm{TiO}_{2}$ while a decrease was found for the $\mathrm{CeO}_{2}$-coating, suggesting non-radiative recombination in the $\mathrm{CeO}_{2}$-coating (process 3 in Figure 5), most likely at structural defects. This conclusion is supported by HR-TEM analysis of the $\mathrm{TiO}_{2}$ - and $\mathrm{CeO}_{2}$ - layers, shown in Figure 7.

The $\mathrm{TiO}_{2}$ layer consists of an amorphous matrix with embedded grains that have a diameter of approximately the same size as the film thickness. In contrast, the $\mathrm{CeO}_{2}$ film is 
polycrystalline, showing differently orientated grains with a grain-size equal to the film thickness and large-angle grain boundaries. The $\mathrm{Al}_{2} \mathrm{O}_{3}$ film is amorphous.
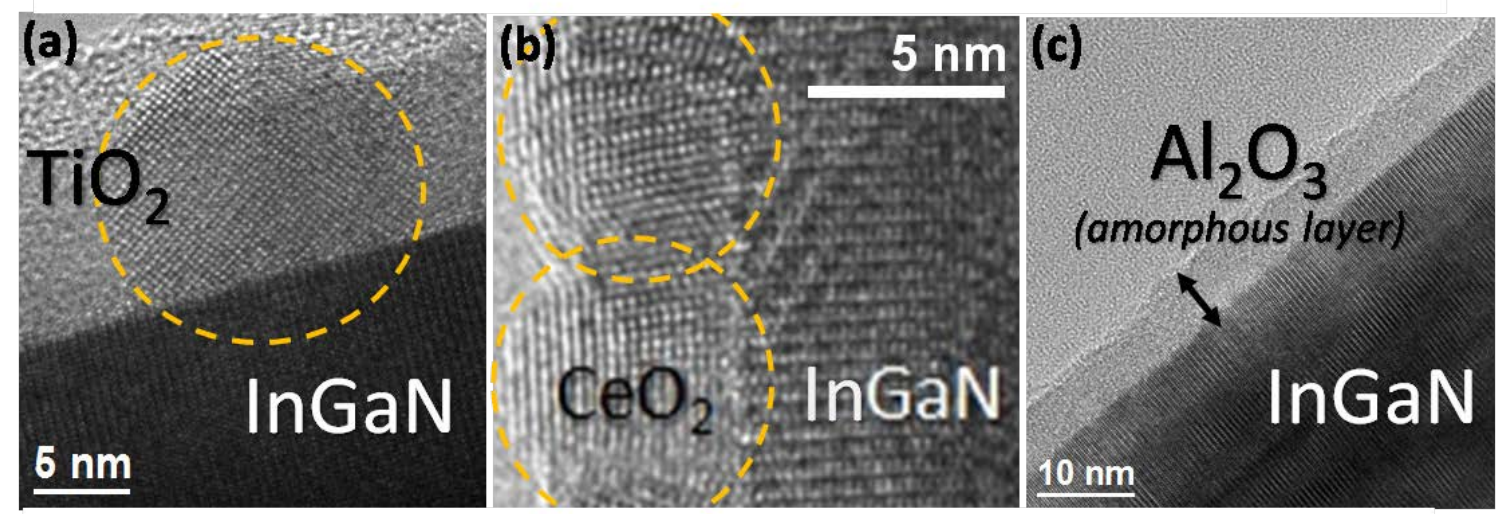

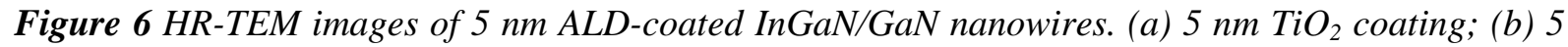
$\mathrm{nm} \mathrm{CeO} \mathrm{O}_{2}$ coating; (c) $5 \mathrm{~nm} \mathrm{Al}_{2} \mathrm{O}_{3}$ coating.

As $\mathrm{CeO}_{2}$ is known for its high defect ratio due to oxygen vacancies and $\mathrm{Ce}^{3+}$-defects [27], the Ce-oxidation state was estimated by EELS measurements (see supplemental information 3), showing a high degree of $\mathrm{Ce}^{3+}$-defects, especially at the surface. Both, the large angle grain boundaries and the oxygen vacancies/ $\mathrm{Ce}^{3+}$-defects could give rise to an enhanced defect recombination rate in the $\mathrm{CeO}_{2}$-coating compared to the $\mathrm{TiO}_{2}$-film.

The surface recombination of photo-generated holes as minority carriers (process 4) with electrons in surface states was investigated for all different coating materials. For this purpose, the PC was measured in the presence of $\mathrm{Na}_{2} \mathrm{SO}_{3}$ that was added as a "hole scavenger" (hs) to the electrolyte solution. As such, it suppresses surface recombination by fast trapping of photogenerated holes before they undergo non-radiative surface recombination. The effect of the hs on the PC was comparatively analyzed for all samples including the reference. In Figure 8 the PCs measured in the presence of the hs, normalized to a PC measured without hs on the same sample is shown. The magnitude of this ratio is a measure for the surface recombination velocity of the respective sample without hs. 


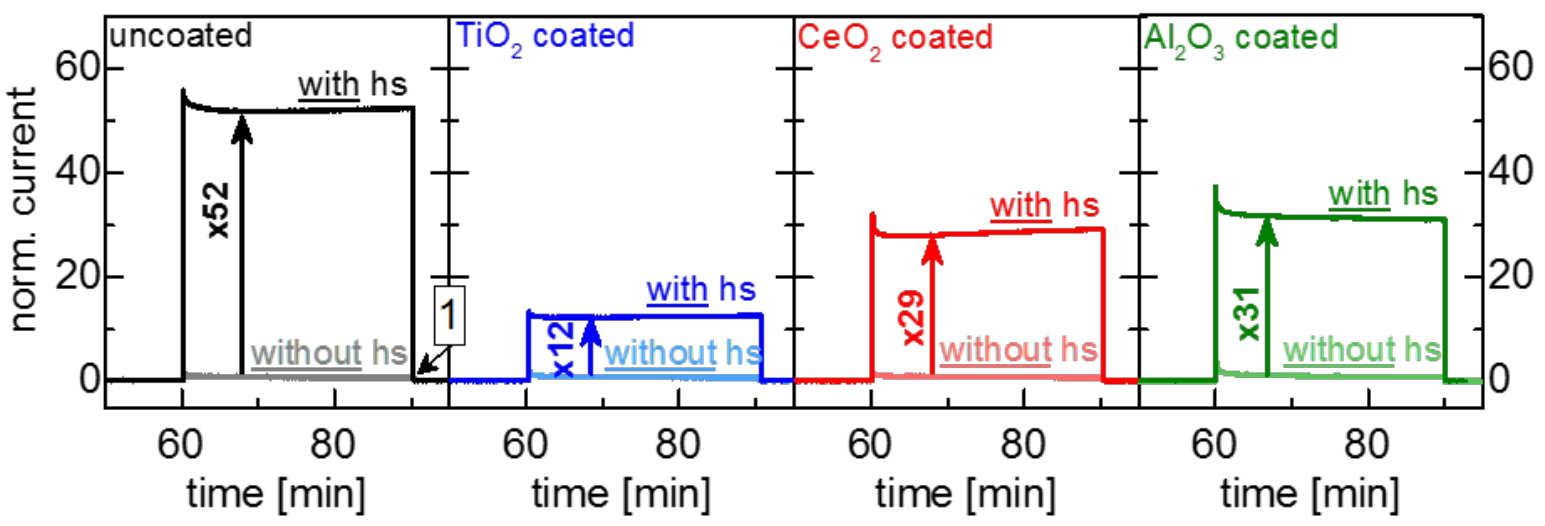

Figure 7 Influence of the presence of $\mathrm{Na}_{2} \mathrm{SO}_{3}$ as hole scavenger in the electrolyte. Photocurrent measurements at $700 \mathrm{mV}$ anodic bias are shown for uncoated, $\mathrm{TiO}_{2}$, $\mathrm{CeO}_{2}$ - and $\mathrm{Al}_{2} \mathrm{O}_{3}$-coated $\mathrm{InGaN}$ $N W s$, each sample measured without and with hs. All measurements are normalized to the respective measurement without hs. Arrows indicate the increase of photocurrent caused by the addition of hole scavenger.

For the bare InGaN/GaN NWs the photocurrent is increased by a factor of 52 when the hole scavenger is added to the electrolyte, while the influence is much lower for samples with $5 \mathrm{~nm}$ thin films of the different oxides $\left(+\mathrm{TiO}_{2}: \mathrm{x} 12 ;+\mathrm{CeO}_{2}: \mathrm{x} 29 ;+\mathrm{Al}_{2} \mathrm{O}_{3}: \mathrm{x} 31\right)$. Consequently, for the $\mathrm{TiO}_{2}$ coated samples the surface recombination is lowest and reduced by a factor of 5 compared to the uncoated reference. These results show that the reduction of surface recombination velocity is an important contribution to the enhancement of the photocurrent of oxide-coated InGaN NWs.

Comparing the three different oxide coatings, the results above show that only for the $\mathrm{TiO}_{2}$ the reduced surface recombination velocity overcompensates the additional loss processes induced by the oxide film, thereby leading to a significant enhancement of the PC. For the $\mathrm{CeO}_{2}$-coated samples, the additional loss processes in the coating are dominant while the huge band discontinuities suppress a transfer of photogenerated carriers in the case of $\mathrm{Al}_{2} \mathrm{O}_{3}$ coating.

The presence of the hs has also impact on the bias-dependence of PC and PL. In Figure 9 this is exemplarily shown for the sample coated with a $5 \mathrm{~nm} \mathrm{TiO}_{2}$ film. Figure 9a demonstrates that the main influence of the hole scavenger on the photocurrent is a shift of the onset potential (minimum potential to observe a PC) to the cathodic direction. This indicates that the open circuit potential (OCP) is also shifted (measured OCPs are marked by vertical lines: - 
$330 \mathrm{mV} \rightarrow-605 \mathrm{mV}$ ) and therefore a higher carrier separation e.g. higher photocurrent at a given potential is gained.

The shift of OCP can be explained by an enhanced occupation of electron surface states in the presence of the hs, since the recombination with photogenerated holes is suppressed.

In Figure 9b the influence of a hole scavenger on the bias-dependent PL intensity is shown. In this case two effects of the hole scavenger are observed: A general offset to lower PL intensities and a shift in the direction of cathodic bias. The latter is a consequence of decreasing OCP, leading to strongly reduced PL intensities only in the cathodic regime. In the anodic regime however, only a small decrease of PL intensity is observed as the curves are already in saturation.
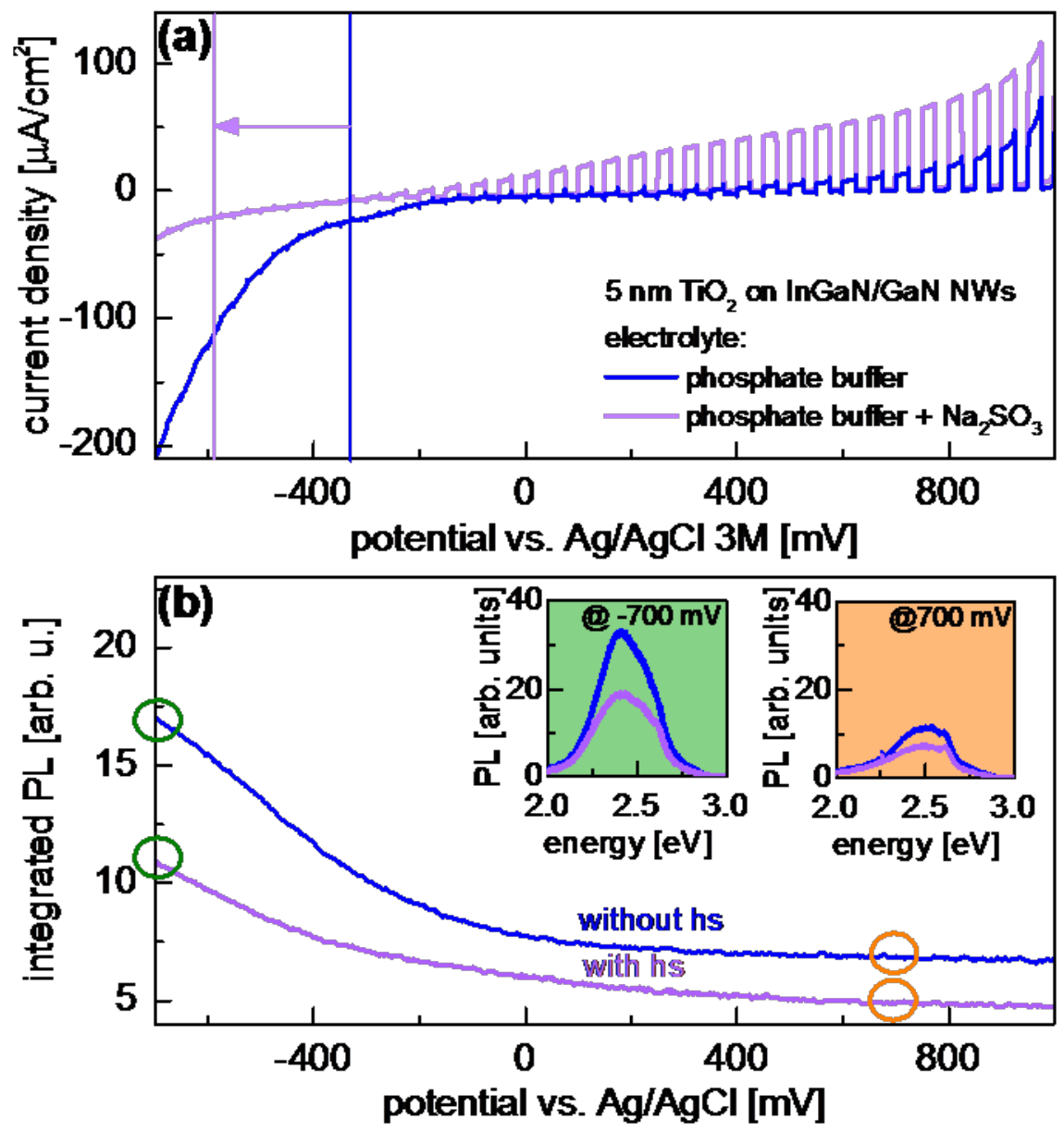

Figure 8 Influence of hole scavenger on the bias dependent $P C$ and $P L$ - example of a $5 \mathrm{~nm} \mathrm{TiO}_{2}$ coated sample. (a) Bias dependent PC measurements in electrolyte with and without hs. The hs shifts the open circuit potential indicated by the arrow and vertical lines leading to a PC increase. Excitation wavelength was $523 \mathrm{~nm}$. (b) Bias dependent PL measurements in electrolyte with and without hs. Insets show the PL-spectra at $-700 \mathrm{mV}$ resp. $+700 \mathrm{mV}$; biases are marked by colored circles on the curves. Excitation wavelength was $405 \mathrm{~nm}$. 


\section{Influence of coating thickness}

The carrier recombination in the $\mathrm{TiO}_{2}$-coating was further investigated by analyzing the evolution of the PC with the thickness of the coating (2, 5, 7, 10 and $15 \mathrm{~nm}$ ). In Figure 10a the resulting dependence of the PC on the thickness is shown. At $t=0$ the resulting photocurrent increases with decreasing film thickness, were a 2 and $5 \mathrm{~nm}$ coating lead to an increase and a 7-15 nm coating lead to a decrease of PC compared to the uncoated reference sample. This trend can be attributed to an enhancement of defect recombination in the coating for increased layer thickness (process 3).

However, the transient PC behavior strongly depends on the film thickness: For film thicknesses $<7 \mathrm{~nm}$ a degradation of the PC with time can be observed. The intensity loss is highest for the uncoated reference and the $2 \mathrm{~nm} \mathrm{TiO}_{2}$ coated sample and less pronounced for the sample with a $5 \mathrm{~nm} \mathrm{TiO}_{2}$ coating. Films with thicknesses $\geq 7 \mathrm{~nm}$ show very stable photocurrents in the contrast. We attribute the permanent degradation to the anodic oxidation of the InGaN for the thin films, while the higher film thicknesses serve as protection-layer. The observed differences in long term stability lead to the fact, that after some measurement time even nanowires with $\mathrm{TiO}_{2}$-film thicknesses of $\geq 7 \mathrm{~nm}$ lead to increased PCs compared to the uncoated sample. Therefore, a film thickness of 5-7 nm seems to be the best compromise between long term stability and photocurrent enhancement.

Measurements in hole scavenger (Figure 10b) result in a strong increase of PC for the reference and the 2-5 nm $\mathrm{TiO}_{2}$ coated samples. Films of 7-10 nm show almost the same PC as without hs. When the hs is added to the electrolyte the anodic oxidation is suppressed and therefore the PC is stable for all samples. 

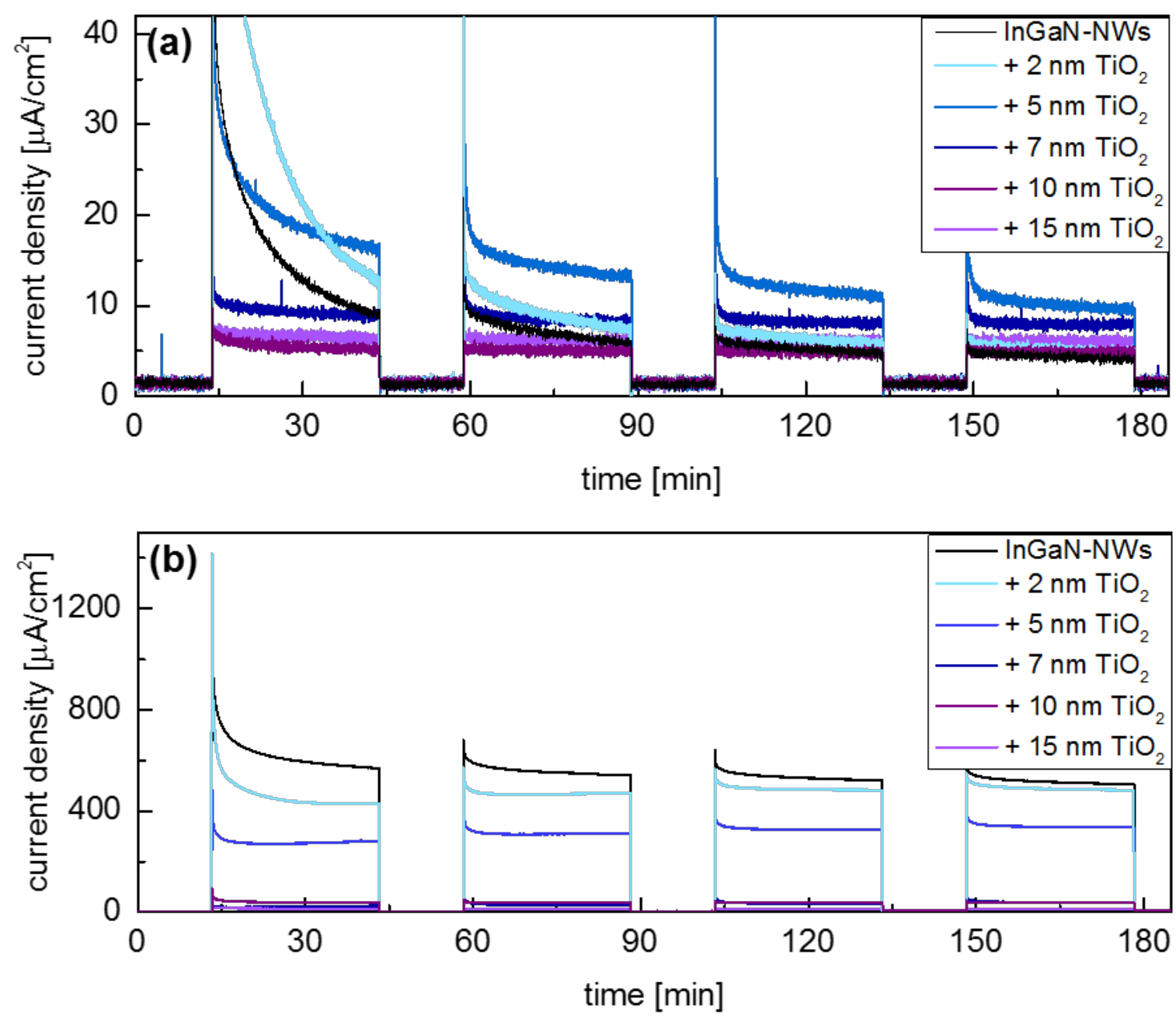

Figure 9 Photocurrent measurements of InGaN nanowires coated with 2, 5, 7, 10 and $15 \mathrm{~nm} \mathrm{TiO}_{2}$ films compared to the uncoated reference sample, measured at $700 \mathrm{mV}$ anodic bias. (a) Measurements in standard electrolyte; (b) Measurements in hole scavenger electrolyte ( $\mathrm{Na}_{2} \mathrm{SO}_{3}$-containing).

\section{Conclusion}

he in uence of ultra-thin $\mathrm{TiO}_{2}, \mathrm{CeO}_{2}$ and $\mathrm{Al}_{2} \mathrm{O}_{3}$ coatings on the photoelectrochemical performance of InGaN NWs on GaN NW templates was comparatively analyzed. All investigated coating materials were deposited by ALD. They are transparent for the 30 investigated excitation wavelength of $405 \mathrm{~nm}$ and their band edge positions straddle the redox levels for water splitting. It was demonstrated that the presence of a $5 \mathrm{~nm} \mathrm{TiO}_{2}$ coating enhances the anodic PC of uncoated InGaN/GaN NWs by a factor of 2.5, which is attributed to the passivation of surface states.

In contrast, for $5 \mathrm{~nm}$ coatings with $\mathrm{CeO}_{2}$ or $\mathrm{Al}_{2} \mathrm{O}_{3}$ the passivation of surface states could also be proved by analysis in hole scavenger electrolyte, but did not lead to an enhancement of the PC, as other recombination processes were enhanced. For $\mathrm{Al}_{2} \mathrm{O}_{3}$, the high band offset to InGaN suppresses the transfer of photocarriers and results in an enhancement of radiative recombination. In the case of $\mathrm{CeO}_{2}$ additional carrier losses are introduced by increased defect recombination in the layer. 
While an enhancement of the PC was observed for $\mathrm{TiO}_{2}$ coatings with thicknesses of $2 \mathrm{~nm}$ and $5 \mathrm{~nm}$, an increased thickness of $7 \mathrm{~nm}$ to $15 \mathrm{~nm}$ results in a decrease of the PC due to recombination in the coating.

For longer operation times the anodic PC of uncoated InGaN/GaN NWs stabilizes on a decreased level as a conse- quence of photoanodic oxidation. While this degradation effect is reduced for a coating thickness up to $5 \mathrm{~nm}$ it is completely suppressed for a thickness of $7 \mathrm{~nm}$ and more.

Consequently, ultra-thin $\mathrm{TiO}_{2}$ coatings with a thickness of $5 \mathrm{~nm}$ and $7 \mathrm{~nm}$ provide a stable enhancement of the photo- current of InGaN/GaN NWs for photoelectrochemical application. In addition, due to efficient transfer of photocarriers, the resulting composite nanostructures consisting of a photoactive ${ }_{1}$ InGaN core and a functional $\mathrm{TiO}_{2}$ coating provide the possibility of triggering photochemical reactions at the $\mathrm{TiO}_{2}$ surface with subbandgap excitation.

\section{Experimental}

\section{MBE growth of InGaN/GaN nanowires}

$\mathrm{In}_{\mathrm{x}} \mathrm{Ga}_{1-\mathrm{x}} \mathrm{N} / \mathrm{GaN}$ nanowire heterostructures were grown on n-type $\mathrm{Si}(111)$ substrates (Asdoped, $\rho<0.01 \Omega \cdot \mathrm{cm}$ ) by plasma-assisted molecular beam epitaxy (PAMBE) using a selfassembled growth process under nitrogen rich conditions [19]. Figure 1a shows a SEM image and the schematic structure of the used InGaN nanowires (NWs). They have a diameter of approximately 50-80 $\mathrm{nm}$ and a density of ca. $100 \mathrm{NW} / \mu^{-2}$, both estimated from SEM top view images, and consist of a $\mathrm{GaN}$ base with a length of $350 \mathrm{~nm}$ (for $\mathrm{Al}_{2} \mathrm{O}_{3}$-coating and reference) resp. $600 \mathrm{~nm}$ (for $\mathrm{TiO}_{2}$-, $\mathrm{CeO}_{2}$-coating and references) and an $\operatorname{In}_{\mathrm{x}} \mathrm{Ga}_{1-\mathrm{x}} \mathrm{N}$ top section with a length of 300-350 nm (estimated from growth rates taken from pure GaN nanowire growth for the GaN base and TEM-images for the InGaN). From the position of the photoluminescence emission a bandgap of $2.3-2.6 \mathrm{eV}(530-480 \mathrm{~nm})$ was estimated for the $\operatorname{In}_{\mathrm{x}} \mathrm{Ga}_{1-\mathrm{x}} \mathrm{N}(\mathrm{InGaN})$ at room temperature. Using the room temperature band gap values $\mathrm{E}_{\mathrm{GaN}}=$ $3.44 \mathrm{eV}, \mathrm{E}_{\mathrm{InN}}=0.76 \mathrm{eV}$ and $\mathrm{b}=1.4 \mathrm{eV}$ taken from [20] this results in an indium content of $\mathrm{x}=0.22-0.31$. However, the In-content determined from XRD measurements is 0.1 , indicating an inhomogeneous In-distribution and preferential recombination in In-rich regions.

\section{ALD deposition of oxide films}

The NWs were coated with thin films of $\mathrm{CeO}_{2}, \mathrm{TiO}_{2}$ and $\mathrm{Al}_{2} \mathrm{O}_{3}$ with different layer thickness using atomic layer deposition (ALD) (cf. TEM image and schematic in Figure 1b). Uncoated reference pieces for each sample were comparatively analyzed. 
For ALD of $\mathbf{C e O}_{2} \mathrm{Ce}(\text { thd })_{4}$ and ozone were used as precursors at a deposition temperature of $270{ }^{\circ} \mathrm{C}$ [21]. 400 ALD-cycles were used for a nominal film thickness of $5 \mathrm{~nm}$ (HR-TEM: 5.8 $\pm 0.7 \mathrm{~nm}$ ). The deposition of $\mathrm{CeO}_{2}$ was verified by EELS analysis. The size of the indirect band gap was estimated from a Tauc plot obtained by transmission measurements of a $5 \mathrm{~nm}$ $\mathrm{CeO}_{2}$ film on quartz glass as reference and is about $2.9 \mathrm{eV}$ (see supplemental information 1) (Lit: $3.2 \mathrm{eV}$ [22]).

ALD of $\mathbf{T i O}_{2}$ films was carried out at a temperature of $200{ }^{\circ} \mathrm{C}$ using $\mathrm{TiCl}_{4}$ and water as precursors. 60, 150, 210, 300 and 450 cycles were used to gain nominally 2, 5, 7, 10 and 15 $\mathrm{nm}$ thin films (HR-TEM of 2, 5 and $10 \mathrm{~nm}$ film: $2.2 \pm 0.3 \mathrm{~nm}, 4.9 \mathrm{~nm}$ with grains of up to 8 nm included; $9.0 \pm 1.5 \mathrm{~nm})$. EELS measurements showed the deposition of anatase $\mathrm{TiO}_{2}$. From transmission measurements on a $5 \mathrm{~nm} \mathrm{TiO}_{2}$ film on quartz glass as a reference an indirect band gap of $3.1 \mathrm{eV}$ was determined from Tauc plot (see supplemental information 1) (Lit.: $3.2 \mathrm{eV}[23])$.

$\mathbf{A l}_{2} \mathbf{O}_{3}$ coatings were deposited at a substrate temperature of $250{ }^{\circ} \mathrm{C}$ using trimethylaluminium (TMA) and water as precursors. 55 cycles were used for a nominal film thickness of $5 \mathrm{~nm}$ (HR-TEM: $4.6 \pm 1.6 \mathrm{~nm}$ ). The deposition of $\mathrm{Al}_{2} \mathrm{O}_{3}$ on a reference planar film of the same film thickness on a silicon substrate was verified by XPS. The $\mathrm{Al}_{2} \mathrm{O}_{3}$ was optically transparent in the entire experimentally accessible wavelength range.

\section{Acknowledgements}

Financial support is provided by the DFG via the GrK (Research training group) 2204 "Substitute Materials for sustainable Energy Technologies." MC thanks Ram on y Cajal program RYC- 2013-12448. We also acknowledge nancial support from the Spanish Ministry of Economy and Competitiveness, through the "Severo Ochoa" Programme for Centres of Excellence in R\&D (SEV-2015-0496). This article is based upon work from COST Action MP1402 "Hooking together European research in atomic layer deposition (HERALD)”, supported by COST (European Cooperation in Science and Technology). SMS acknowledges funding from "Programa Internacional de Becas "la Caixa"- Severo Ochoa". JA, MdlM. and SMS also acknowledge funding from Generalitat de Catalunya 2014 SGR 1638 and the Spanish MINECO e-TNT (MAT2014-59961-C2-2-R). ICN acknowledges support from the Severo Ochoa Program (MINECO, Grant SEV- 2013-0295) and is funded by the CERCA Programme/Generalitat de Catalunya. The atomic resolution HAADF-STEM microscopy was conducted in the Laboratorio de Microscopias Avanzadas at the Instituto de Nanociencia de Aragon-Universidad de Zaragoza. JA and SMS thank them for offering access to their instruments and expertise. Part of the present work has been performed in the framework of Universitat Aut onoma de Bar- celona Materials Science PhD program. RM gratefully acknowledges funding in the Emmy-Noether program (MA 5392/3-1) of the German Research Foundation DFG. 


\section{Literature}

[1] J. Chen, D. Yang, D. Song, J. Jiang, A. Ma, M. Z. Hu, and C. Ni, Recent progress in enhancing solar-to-hydrogen efficiency, Journal of Power Sources 280 (2015), 649-666, http://dx.doi.org/10.1016/j.jpowsour.2015.01.073.

[2] R. Abe, Recent progress on photocatalytic and photoelectrochemical water splitting under visible light irradiation, Journal of Photochemistry and Photobiology C: Photochemistry Reviews 11 (2010), 179-209, http://dx.doi.org/10.1016/j.jphotochemrev.2011.02.003.

[3] M. Ni, M. K. Leung, D. Y. Leung, and K. Sumathy, A review and recent developments in photocatalytic water-splitting using $\mathrm{TiO}_{2}$ for hydrogen production, Renewable and Sustainable Energy Reviews 11 (2007), 401-425, http://dx.doi.org/10.1016/j.rser.2005.01.009.

[4] C. G. Van de Walle and J. Neugebauer, Universal alignment of hydrogen levels in semiconductors, insulators and solutions, Nature 423 (2003), 626-628, http://dx.doi.org/10.1038/nature01665.

[5] P. G. Moses, M. Miao, Q. Yan, and C. G. Van de Walle, Hybrid functional investigations of band gaps and band alignments for AlN, GaN, InN, and InGaN, J. Chem. Phys. 134 (2011), 084703, http://dx.doi.org/10.1063/1.3548872.

[6] K. Fujii, T. Karasawa, and K. Ohkawa, Hydrogen Gas Generation by Splitting Aqueous Water Using n-Type GaN Photoelectrode with Anodic Oxidation, Japanese Journal of Applied Physics 44 (2005), L543-L545, http://dx.doi.org/10.1143/jjap.44.1543.

[7] K. Fujii and K. Ohkawa, Photoelectrochemical Properties of p-Type GaN in Comparison with nType GaN, Japanese Journal of Applied Physics 44 (2005), L909-L911, http://dx.doi.org/10.1143/jjap.44.1909.

[8] K. Fujii, K. Kusakabe, and K. Ohkawa, Photoelectrochemical Properties of InGaN for H2 Generation from Aqueous Water, Japanese Journal of Applied Physics 44 (2005), 7433-7435, http://dx.doi.org/10.1143/jjap.44.7433.

[9] J. Juodkazyte, B. Sebeka, I. Savickaja, A. Kadys, E. Jelmakas, T. Grinys, S. Juodkazis, K. Juodkazis, and T. Malinauskas, $\operatorname{In}_{\mathrm{x}} \mathrm{Ga}_{1-\mathrm{x}} \mathrm{N}$ performance as a band-gap-tunable photoelectrode in acidic and basic solutions, Solar Energy Materials and Solar Cells 130 (2014), 36-41, http://dx.doi.org/10.1016/j.solmat.2014.06.033.

[10] J. Li, J. Y. Lin, and H. X. Jiang, Direct hydrogen gas generation by using InGaN epilayers as working electrodes, Applied Physics Letters $93 \quad$ (2008), 162107, http://dx.doi.org/10.1063/1.3006332.

[11] A. Theuwis, K. Strubbe, L. M. Depestel, and W. P. Gomes, A Photoelectrochemical Study of $\mathrm{In}_{\mathrm{x}} \mathrm{Ga}_{1-\mathrm{x}} \mathrm{N}$ Films, Journal of The Electrochemical Society 149 (2002), E173, http://dx.doi.org/10.1149/1.1468647

[12] M. Ono, K. Fujii, T. Ito, Y. Iwaki, A. Hirako, T. Yao, and K. Ohkawa, Photoelectrochemical reaction and $\mathrm{H}_{2}$ generation at zero bias optimized by carrier concentration of n-type GaN, J. Chem. Phys. 126 (2007), 054708, http://dx.doi.org/10.1063/1.2432116.

[13] B. AlOtaibi, H. P. T. Nguyen, S. Zhao, M. G. Kibria, S. Fan, and Z. Mi, Highly Stable Photoelectrochemical Water Splitting and Hydrogen Generation Using a Double-Band InGaN/GaN Core/Shell Nanowire Photoanode, Nano Lett. 13 (2013), 4356-4361, http://dx.doi.org/10.1021/nl402156e.

[14] M. Ebaid, J.-H. Kang, S.-H. Lim, J.-S. Ha, J. K. Lee, Y.-H. Cho, and S.-W. Ryu, Enhanced solar hydrogen generation of high density, high aspect ratio, coaxial InGaN/GaN multi-quantum well nanowires, Nano Energy 12 (2015), 215-223, http://dx.doi.org/10.1016/j.nanoen.2014.12.033.

[15] D. Wang, A. Pierre, M. G. Kibria, K. Cui, X. Han, K. H. Bevan, H. Guo, S. Paradis, A.-R. Hakima, and Z. Mi, Wafer-Level Photocatalytic Water Splitting on GaN Nanowire Arrays Grown by Molecular Beam Epitaxy, Nano Lett. 11 (2011), 2353-2357, http://dx.doi.org/10.1021/nl2006802. 
[16] M. G. Kibria, H. P. T. Nguyen, K. Cui, S. Zhao, D. Liu, H. Guo, M. L. Trudeau, S. Paradis, A.-R. Hakima, and Z. Mi, One-Step OverallWater Splitting under Visible Light Using Multiband InGaN/GaN Nanowire Heterostructures, ACS Nano 7 (2013), 7886-7893, http://dx.doi.org/10.1021/nn4028823.

[17] T. Kehagias, G. P. Dimitrakopulos, P. Becker, J. Kioseoglou, F. Furtmayr, T. Koukoula, I. Häusler, A. Chernikov, S. Chatterjee, T. Karakostas, and et al., Nanostructure and strain in InGaN/GaN superlattices grown in GaN nanowires, Nanotechnology 24 (2013), 435702, http://dx.doi.org/10.1088/0957-4484/24/43/435702.

[18] R. Liu, Z. Zheng, J. Spurgeon, and X. Yang, Enhanced photoelectrochemical water-splitting performance of semiconductors by surface passivation layers, Energy \& Environmental Science 7 (2014), 2504, http://dx.doi.org/10.1039/c4ee00450g.

[19] J. Wallys, J. Teubert, F. Furtmayr, D. M. Hofmann, and M. Eickhoff, Bias-Enhanced Optical pH Response of Group III-Nitride Nanowires, Nano Lett. 12 (2012), 6180-6186, http://dx.doi.org/10.1021/nl303021v.

[20] I. Vurgaftman, J. R. Meyer, and L. R. Ram-Mohan, Band parameters for III-V compound semiconductors and their alloys, Journal of Applied Physics 89 (2001), 5815-5875, http://dx.doi.org/10.1063/1.1368156

[21] M. Coll, J. Gazquez, A. Palau, M. Varela, X. Obradors, and T. Puig, Low Temperature Epitaxial Oxide Ultrathin Films and Nanostructures by Atomic Layer Deposition, Chemistry of Materials 24 (2012), 3732-3737, http://dx.doi.org/10.1021/cm301864c.

[22] Z.-M. Yang, G.-F. Huang, W.-Q. Huang, J.-M. Wei, X.-G. Yan, Y.-Y. Liu, C. Jiao, Z. Wan, and A. Pan, Novel Ag 3 PO 4 /CeO 2 composite with high efficiency and stability for photocatalytic applications, J. Mater. Chem. A 2 (2014), 1750-1756, http://dx.doi.org/10.1039/c3ta14286h.

[23] Y. Xu and M. A. Schoonen, The absolute energy positions of conduction and valence bands of selected semiconducting minerals, American Mineralogist 85 (2000), 543-556, http://dx.doi.org/10.2138/am-2000-0416.

[24] L. Caccamo, G. Cocco, G. Martin, H. Zhou, S. Fundling, A. Gad, M. S. Mohajerani, M. Abdelfatah, S. Estrade, F. Peiro, and et al., Insights into Interfacial Changes and Photoelectrochemical Stability of $\operatorname{In}_{\mathrm{x}} \mathrm{Ga}_{1-\mathrm{x}} \mathrm{N}$ (0001) Photoanode Surfaces in Liquid Environments, ACS Applied Materials \& Interfaces 8 (2016), 8232-8238, http://dx.doi.org/10.1021/acsami.5b12583.

[25] G. Chmiel and H. Gerischer, Photoluminescence at a semiconductor-electrolyte contact around and beyond the flat-band potential, J. Phys. Chem.-US 94 (1990), 1612-1619, http://dx.doi.org/10.1021/j100367a072.

[26] S. Xu, R. M. Jacobs, H. M. Nguyen, S. Hao, M. Mahanthappa, C.Wolverton, and D. Morgan, Lithium transport through lithium-ion battery cathode coatings, J. Mater. Chem. A 3 (2015), 1724817272, http://dx.doi.org/10.1039/c5ta01664a.

[27] A. Trovarelli, Catalytic properties of ceria and CeO2-containing materials, Catalysis Reviews 38 (1996), 439-520, http://dx.doi.org/10.1080/01614949608006464. 